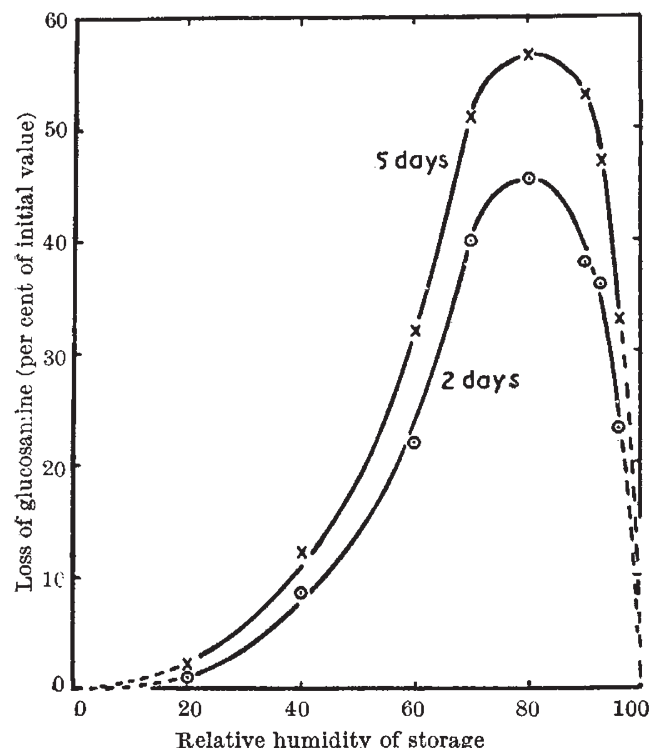

Destruction of glucosamine in a freeze-dried casein-glucosamine mixture of initial $p \mathrm{H} 6 \cdot 3$ when stored for two and five days at
$37^{\circ} \mathrm{C}$. and various relative humidities

expected to be stable, the protein in the semi-dry state apparently neutralizing the hydrochloric acid and leaving the free base to react in the water film on the protein surface.

A comparable phenomenon was observed when $\mathrm{N}$-acetyl-D-glucosamine was dried and stored in the same way with casein. After storage the reaction product was found to react in the Morgan and Elson method for $\mathrm{N}$-acetyl-glucosamine ${ }^{5}$ without the preliminary treatment with alkali, to give a colour spectroscopically identical with that obtained in the normal method. This indicates that the isomerization and condensation to the oxazole ring, which is usually brought about by boiling with $0.5 \mathrm{~N}$ sodium carbonate, had proceeded on the surface of the 'dry' protein.

In both these reactions the surface of the protein appears to have provided a more alkaline environment than would be expected from the $p H$ of the solution from which it was dried. Such factors must obviously be included in consideration of deterioration of the browning type in dried foodstuffs, where degradation and caramelization of carbohydrate frequently occurs under conditions of $p \mathrm{H}$ at which the sugars alone would be stable.

Attention should also be directed to the possibility of destruction, by routes similar to that described, of 2-amino sugars during isolation procedures, especially if solutions are evaporated to dryness even at moderate temperature. Losses of chondrosamine (2-amino-L-galactose) have, for example, been observed during separation from hydrolysates by the use of anion exchange columans ${ }^{6}$, and other cases of loss of amino-sugars have been reported in the literature?

The nature of the products from the glucosamine reaction is at present under investigation; a major component probably results from the condensation of two molecules of the $\alpha$-amino aldehyde to form a pyrazine derivative, but several substances are present, some of them dark coloured.

This work was carried out as part of the programme of the Food Investigation Organization of the Depart- ment of Scientific and Industrial Research. A full account will be published elsewhere.

C. H. LEA

D. N. RHODES

S. BORRELI

Low Temperature Station for Research in Biochemistry and Biophysics,

University of Cambridge and Department of Scientific and Industrial Research. Jan. 10.

${ }^{1}$ Lea, C. H., and Rhodes, D. N., Biochim. Biophys. Acta (in the press). 2 Lea, C. H., and Hannan, R. S., Biochim. Biophys. Acta, 3, 313 (1949); Biochem. J., 47, $626(1950)$.
Biochem. J., [50, $713(1952)$.

${ }^{3}$ Hannan, R. S., and Lea, C. H., Biochim. Biophys. Acta (in the press!.

${ }^{4}$ Elson, L. A., and Morgan, W. T. J., Biochem. J., 27, 1824 (1933).

${ }^{5}$ Morgan, W. T. J., and Elson, L. A., Biochem. J., 28, 988 (1934).

'Partridge, S. M. (private communication).

${ }^{7}$ Meyer, K., "Advances Protein Chem.", 2, 256 (1944).

\section{Populations of Agrostis tenuis Resistant to Lead and Zinc Poisoning}

IN order to find out on how small a scale ecological differentiation can occur, a study is being made of the differentiation in the grass Agrostis tenuis in the region around Aberystwyth. Samples of sixty separate tillers taken at random from each of a number of different habitats have been cultivated, suitably laid out in trial, in an experimental garden. A considerable amount of very local differentiation has been found, an account of which will be published elsewhere.

Of the populations sampled, one was from a disused lead mine known to be at least a thousand years old at Goginan, five miles from Aberystwyth, and another from an ordinary Agrostis-Festuca pasture a short distance away. The soil of the mine contains approximately 1 per cent lead and 0.03 per cent zinc mostly as sulphate and sulphide and carries no plant life except Agrostis tenuis. The pasture is uncontaminated. On cultivation in normal soil, the sample from the mine is distinctly smaller and grows more slowly. On being transplanted as tillers into soil from the mine, the mine sample grew normally while the pasture sample made no growth at all, 50 per cent of the tillers being more or less dead in three months. The latter were found to have produced misshapen roots rarely more than $2 \mathrm{~mm}$. long, whereas the former rooted normally. These results were obtained immediately after the initial collection and again after the material had been in cultivation in normal soil for two years. There was no indication of any change in resistance having taken place. The character is practically restricted to the mine population, for only three plants of the pasture sample of sixty showed any real resistance though collected only a hundred yards away.

Further work on this and related population problems is being continued; the genus is being studied from the point of view of taxonomy, cytology and broeding by W. E. Davies, K. Jones and A. Lazenby of the Welsh Plant Breeding Station, Aberystwyth.

\section{A. D. Bradshaw}

Department of Agricultural Botany, University College of North Wales,

Bangor.

Jan. 18 